\title{
Preschool cognitive control and family adversity predict the evolution of classroom engagement in elementary school
}

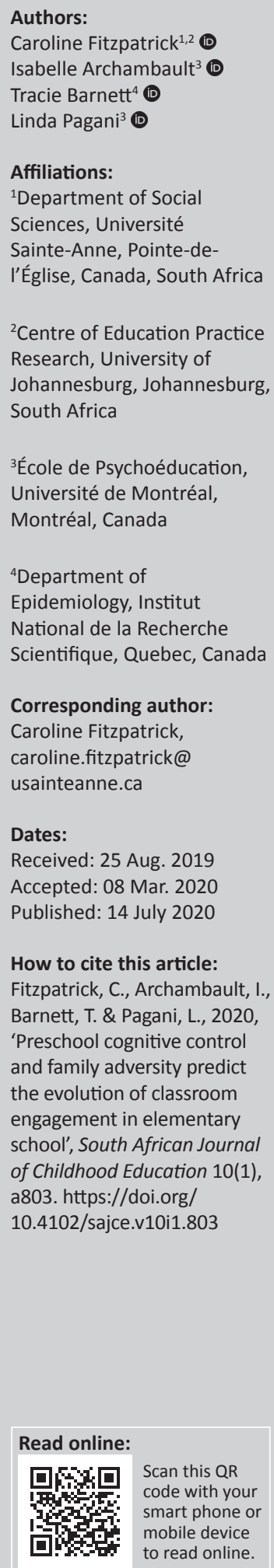

Background: Classroom engagement is key predictor of child academic success.

Aim: The objective of the study was to examine how preschool cognitive control and the experience of family adversity predict developmental trajectories of classroom engagement through elementary school.

Setting: Children were followed in the context of the Quebec Longitudinal Study of Child Development from birth to age $10.5(N=1589)$.

Methods: Working memory was directly assessed when children were 3 years old and mothers reported child impulsivity, parenting characteristics, stress and social support when children were 4 years old. Elementary school teachers rated classroom engagement from kindergarten through Grade 4.

Results: Growth mixture modelling identified three distinct trajectories of classroom engagement. Child working memory and impulsivity, and maternal hostility, social support and stress predicted greater odds of belonging to the low versus high engagement trajectory. Child impulsivity and maternal hostility and stress also distinguished between the low and moderate engagement trajectories.

Conclusion: Our results suggest that targeting preschool cognitive control and buffering the effects of family adversity on children may facilitate academic success.

Keywords: classroom engagement; learning-related behaviour; working memory; impulsivity; parenting; parental stress; person-centred.

\section{Introduction}

The current economic burden of academic underachievement and high school dropout remains high and demands that we increase our understanding of which children may be at risk of experiencing poor academic outcomes (Levin et al. 2007; Stetser \& Stillwell 2014; Uppal 2017). Although acquiring a solid base in math and languages is important for lifelong learning and achievement, a focus solely on knowledge-based skills overlooks a theoretically meaningful component. Indeed, constructivist and metacognitive theories of learning recognise that classroom learning is a self-directed process that depends on the active involvement of students (Hartman 1998; Sodian \& Frith 2008; Tobin \& Tippins 1993).

Research evidence supports the idea that self-regulated, engaged learners benefit more from educational experiences (Daniel, Wang \& Berthelsen 2016; Dent \& Koena 2016). Classroom engagement falls into the broader category of learning-related behaviours and reflects student ability to follow instructions, complete tasks on time and self-organise in the classroom (Fitzpatrick \& Pagani 2013; Ladd \& Dinella 2009). Kindergarten teacher assessments of classroom engagement predict later academic success and higher quality relationships with teachers and peers (Fitzpatrick \& Pagani 2013).

Among high school students, individual differences exist in trajectories of engagement over time and these patterns predict academic outcomes (Reeve \& Lee 2014; Wang \& Fredericks 2014). Less is known about how classroom engagement evolves over the course of elementary school and what individual child and family characteristics predict the course of these trajectories. 


\section{Predictors of classroom engagement}

As have others, we conceptualise classroom engagement as being driven by individual differences in cognitive control (Li-Grining et al. 2010; Ponitz et al. 2009; Sasser, Bierman \& Heinrichs 2015). Working memory is a component of cognitive control, which is akin to one's mental workspace or desktop where learners can manipulate and update information that they will use in the short term (Bull et al. 2012). Research suggests that working memory contributes to short- and long-term academic success (Fitzpatrick \& Pagani 2012; Fitzpatrick et al. 2015). As such, it is possible that individual difference in preschool working memory predicts the nature and course of classroom engagement throughout elementary school.

Preschool-aged children who arrive at school better able to control and regulate their attentional resources have an easier time-sustaining engaged learning in the classroom (Duncan et al. 2007; Pagani et al. 2010; Razza, Martin \& Brooks-Gunn 2010). In contrast, students who have difficulty inhibiting inappropriate behaviour and who are more distractible may be at greater risk of disengaging from classroom activities. Consequently, it is likely that preschool-aged children who demonstrate attention problems in the form of impulsivity (i.e. not being able to wait their turn, not being able to settle down) will also be less engaged in the elementary school classroom.

Young children's family context and experiences can also influence their capacity for engaged learning. Early life exposure to family adversity and toxic stress has been linked to excessive activation in children's stress response systems (Lupien et al. 2007; Robles et al. 2016; Rutter \& O'Connor 2004). Such chronic activation can then lead to a series of structural and functional alternations in the brain circuitry of the amygdala and hippocampus and prefrontal cortex. Eventually, these alterations are believed to contribute to increased anxiety and poor stress regulation during learning activities and ultimately impair engagement (Arnsten 2009; Shonkoff 2011).

Both positive and adverse rearing environments are likely to shape learning outcomes. Experimental animal research provides compelling evidence that high-quality parenting in terms of maternal responsiveness and warmth can exercise long-term influences on the cognitive development of offspring through epigenetic processes (Champagne \& Curley 2009). Longitudinal research in humans has generated similar findings. For example, maternal warmth in early childhood has been shown to positively influence social and cognitive outcomes in children prior to school entry (Guinosso, Johnson \& Riley 2015; Wade et al. 2015).

Finally, children's broader ecology can also influence their healthy development (Bronfenbrenner 1986; Sameroff 2010). For one, enduring stress that leads to emotional, physical and mental exhaustion in parents may impair effective parenting practices (Schieve et al. 2007). In contrast, parental social support may have a positive effect on child outcomes by increasing the number of resources available to parents (Burchinal, Follmer \& Bryant 1996).

\section{Classroom engagement trajectories}

Little research has employed a person-centred approach to examine how child and family characteristics influence the course of children's learning-related skills across elementary school. Person-centred approaches allow us to identify discrete subgroups of people who follow distinct developmental trajectories over time. Thus, the identification of non-normative risk pathways is particularly germane to intervention and prevention research.

\section{Objectives and hypotheses}

The primary objective of the present study was to identify groups of students that show distinct profiles of classroom engagement in the classroom across the elementary school years (objective 1). Because prior research has identified three clusters of youth who follow distinct trajectories of classroom engagement, we also expect that a three-class model will best describe our data (Pagani et al. 2012). We also examined whether child working memory and impulsivity predict patterns of engagement (objective 2) and family adversity predicts engagement trajectories (objective 3 ). In terms of objectives 2 and 3, a first hypothesis is that better cognitive control will predict higher levels of engagement. We also expect that children whose mothers report more hostility and less warmth and consistent discipline will display lower, more maladaptive patterns of classroom engagement in the elementary classroom. Finally, because they can compromise the availability of parental resources, we expect that children whose mothers report more stress and less social support will be at greater risk of showing lower patterns of classroom engagement. Although these predictions are empirically and theoretically informed, they remain speculative as the parenting characteristics most linked to engagement across elementary school remain unknown.

In the present study, we attempted to take into account child and family characteristics, which may account for observed associations between our predictor variables and classroom engagement trajectories. Math and vocabulary skills at school entry as well as behaviour problems have been shown to influence academic adjustment (Duncan et al. 2007; Pagani et al. 2010). Furthermore, socio-economic status and family configuration were considered as additional potential confounders because they represent proxies for multiple risk factors, including home stimulation, early education, physical health and neighbourhood quality (Bornstein \& Bradley 2003; Hackman \& Farah 2009).

\section{Methods \\ Participants}

The Quebec Longitudinal Study of Child Development (QLSCD 1998-2010) represents a birth cohort randomly selected from a stratified sample of 2837 children born in the province of Quebec, Canada, between 1997 and 1998. The sample was stratified to ensure a proportional representation across rural and urban areas, geographical region, socioeconomic status and gender. At the inception of the 
longitudinal component of this public data set coordinated by the Institut de la Statistique du Québec, 93 children were deemed ineligible and 172 were untraceable because of incorrect coordinates. Of the 2572 remaining children, 14 were unreachable and 438 refused to participate. Thus, for its early childhood phase, 2120 five-month-old infants were deemed eligible for follow-up, representing $82 \%$ of the eligible target population defined by the birth cohort. Of these, 39\% were firstborn. Participants were included in this ethically approved study if they had least one valid classroom engagement score between kindergarten and fourth grade at 74 and 122 months, respectively $(N=1589)$. From the second grade onwards, data collection occurred on a bi-annual basis; therefore, no data are available for the third grade. This subsample represents $79 \%$ from the original sample. Compared to non-retained participants, participants included in the analytic sample were from higher socio-economic status. There were no sample differences in family configuration, child preschool impulsivity, working memory, number knowledge and receptive vocabulary.

\section{Procedure}

For the preschool collection waves, data were collected from children and their families around the date of the child's birthday. The questionnaires were administered predominantly in French, reflecting the linguistic distribution of the province of Quebec, Canada. During the school-aged waves, data collection occurred in the spring. Families, teachers and school principals received informed consent forms by mail at each data collection wave. Teachers and families also received and returned questionnaires by mail. Teachers were informed that each target child had been followed from birth as a part of an ongoing study of development. Teachers were also informed that participation would involve completing a questionnaire concerning the behaviour, academic performance and social skills of the child at school. Parents were also interviewed by phone or in person by a research assistant trained by the government operated Direction of Social Services. Parents were compensated \$25 and were informed that their child would receive a small present.

\section{Measures: Outcome variable}

\section{Classroom engagement}

Teachers rated classroom engagement in kindergarten and grades 1, 2 and 4 after having observed children for approximately 6 months using a seven-item scale (average Cronbach's alpha of all four assessments $=0.92$ ): works and plays cooperatively with other children, follows rules and instructions, follows directions, listens attentively, completes work on time, works autonomously, and works neatly and carefully. Responses ranged from 1 (never) to 3 (always) in kindergarten and 1 (never) to 5 (always) in grades 1, 2 and 4 . Higher scale scores indicated a higher degree of classroom engagement. Given the difference in scaling across study years, all scores were standardised to $z$-scores prior to the estimation of trajectories. This classroom engagement measure is substantially related with academic ability (Fitzpatrick \& Pagani 2013; Pagani et al. 2010).

\section{Measures: Early childhood cognitive control predictors}

\section{Working memory}

At 29 months, the research assistants measured child working memory using an abridged version of the Imitation Sorting Task (Alp 1994). A trained experimenter firstly demonstrated a sequence and then children were asked to correctly reproduce the demonstrated sequence of placing the correct toy in the correct canister. This task has also shown to be a robust predictor of kindergarten readiness at 29 and 41 months (Fitzpatrick \& Pagani 2012).

\section{Impulsivity}

When children were 53 and 65 months, parents completed a nine-item impulsivity scale. Items were rated from 1 (often or very true) to 3 (never or not true) and include the following: could not sit still, was restless and hyperactive; has trouble sticking to any activity; could not stop fidgeting; was impulsive, acted without thinking; had difficulty waiting for his or her turn; could not settle down to do anything for more than a few moments; was easily distracted; was inattentive and was unable to concentrate, and could not pay attention for long time $(\alpha=0.91)$. Means at 53 and 65 months were averaged. Higher scores indicate more impulsivity. Items were derived from the child behaviour checklist (Achenbach, Edelbrock \& Howell 1987), the Ontario Child Health Study Scales (Offord, Boyle \& Racine 1989) and the Canadian Preschool Behavior Questionnaire (Tremblay et al. 1994). These questionnaires have all been previously validated using large longitudinal samples. The predictive validity of this scale was supported by studies showing associations between this measure of impulsivity and adolescent criminal behaviours (Broidy et al. 2003; Nagin \& Tremblay 1999).

\section{Measures: Family adversity predictors}

When children were 53 and 65 months, mothers provided information about three dimensions of parenting practices (hostility, warmth and discipline) using a version of the Parenting Perceptions and Behaviors Questionnaire adapted for 4- and 5-year-olds (Parental Cognitions and Conduct Toward the Infant Scale; Boivin et al. 2005). Items were rated on a five-point Likert scale, ranging from 1 (never) to 5 (always). The Cronbach's alphas for the five parenting factors were calculated based on the present sample.

\section{Maternal hostility}

Mothers responded to seven items related to hostile coercive parenting: 'I have gotten mad with my child because they said or did something they were not supposed to'; 'I have raised my voice, scolded or shouted at my child when he or she misbehaved'; 'I have lost my temper with my child while punishing them'; 'I have used corporal punishment when my child misbehaved'; and 'I have hit my child when they were particularly difficult', $\alpha=0.74$.

Maternal warmth refers to the amount of affection and pleasure mothers express during interactions with their 
child. Items include the following: 'my child and I have spent time talking, playing or focusing attention on each other just for fun for $5 \mathrm{~min}$ or more'; 'I have performed something special with my child that they enjoy'; 'I engage in sports, hobbies or play games with my child'; 'I calmly discuss the problem when my child brakes the rules or misbehaves'; and 'I describe alternative ways of behaving that are acceptable when my child breaks the rules or misbehaves', $\alpha=0.78$.

Parental discipline reflects the use of consistent discipline with the child. Items include the following: 'when I told my child they would get punished if they did not stop doing something, and they kept doing it, so I punished them'; 'my child has gotten away with things that should have been punished (reverse-coded)'; 'my child has gotten out of a punishment when their mind was really set on it (reversecoded)'; 'after being disciplined, my child ignores the punishment (reverse-coded)'; and 'when my child misbehaves, I ignore it or do nothing (reverse-coded)', $\alpha=0.79$.

\section{Maternal stress}

Mothers were asked about their general level of daily stress over the past 12 months using a Likert scale ranging from 1 (never) to 5 (always) when children were 53 months. Higher scores reflect higher levels of stress. Items adapted from the Perceived Stress Scale (Cohen, Tyrrell \& Smith 1993) include the following: 'I felt I had to rush to get everything performed each day'; 'by the time supper time arrived, I was physically exhausted'; and 'I felt I had enough time for myself (reversecoded $)^{\prime}, \alpha=0.75$.

\section{Social support}

Mothers reported perceived social support when children were 53 months using three items adapted from the Arizona Social Support Interview (ASSI) (Barrera \& Garrison-Jones 1992). Mothers rated each item on a Likert scale ranging from 1 (strongly agree) to 4 (strongly disagree): 'I have family and friends who help me feel safe, secure and happy'; 'there is someone I trust whom I would turn to for advice if I were having a problem'; and 'there are people I can count on in an emergency', $\alpha=0.87$.

Means for maternal hostility, warmth, discipline, stress and social support were transformed to a scale ranging from 1 to 10 , with higher scores reflecting higher levels of the construct.

\section{Measures: Control variables}

\section{Child academic skills}

The Number Knowledge Test (NKT, abridged version) was administered individually to children by trained examiners to test the basic knowledge of numbers (Okamoto \& Case 1996). The NKT adapted for testing in 4-year-olds measures the knowledge of the number sequence from 1 to 10, knowledge of the one-to-one correspondence in which a sequence is mapped onto objects being counted, understanding the cardinal value of each number, understanding of the generative rule which relates adjacent cardinal values and understanding that each successive number represents a set which contains more objects. The Peabody Picture Vocabulary Test (PPVT, French adaptation; Dunn, Thériault-Whalen \& Dunn 1993) was also administered by trained examiners to test the vocabulary knowledge. This test consists of 175 vocabulary items that increase in difficulty throughout the test. The French version has been standardised by Dunn et al. (1993) and is highly correlated with other French vocabulary and intelligence tests. Both NKT and PPVT scores represent sums of correct responses.

Parents provided data on additional child and family variables that could possibly influence the key variables in this study. These include child sex and behavioural adjustment in terms of emotional distress (six items: 'seemed to be unhappy or sad', 'was not as happy as other children', 'was no energy was feeling tired, cried much', 'had trouble enjoying him or herself' and 'is unable to make decisions', $\alpha=0.79$ ) and prosocial behaviour (three items: 'tried to help someone who had been hurt', 'comforted a child [friend, brother or sister] who was crying or upset' and 'helped other children [friends, brother or sister] who were feeling sick', $\alpha=0.85$ ). Items were scored in such a manner that a higher value on the scale would indicate a higher degree of the factor. The Social Behaviour Questionnaire represents a good predictor of future psychosocial adjustment and school success (Dobkin et al. 1995; Pagani et al. 2001). All measures reflect the mean of scores from the 53 and 65 month assessments. Socio-economic status was derived from parents' income reports, occupational prestige and level of education. Scores were standardised to a mean of 0 and reflect average scores from 5 to 65 months. Family configuration was reported by parents and was dichotomised to reflect whether the family was intact or not at 17 months.

\section{Data analytic strategy}

Our interest was first to detect trajectories of classroom engagement from kindergarten through grade 4 . We were also interested in examining how early childhood characteristics, parenting and family context contribute to these trajectories. We used growth mixture modelling to estimate distinct intercepts and slopes for groups with unique patterns of the variable of interest (Jung \& Wickrama 2008).We estimated unconditional trajectories because our interest was in first identifying naturally occurring patterns of engagement and then estimating whether these trajectories can be estimated by meaningful predictors at the child and family level. Model selection was based on fit indices, prior research and the ability to account for meaningful diversity in the data (Richters 1997). We first generated a one-group linear model to which a two-group model was compared. Models with additional groups were then tested sequentially against two-, three- and four-group models. We repeated the same process with higher-order growth terms. Based on our criteria, a threegroup quadratic growth model was favoured. Participants were assigned to groups based on their actual most likely classification (Ram \& Grimm 2009). We next examined 
prospective associations between early childhood cognitive control, family adversity and control variables on classroom engagement trajectories using polynomial linear regression.

\section{Missing data}

Missing data on classroom engagement between kindergarten and fourth grade were dealt with during the estimation of trajectories using full information maximum likelihood methods in Mplus (Muthén, Kaplan \& Hollis 1987). Missing data on independent and control variables were handled with using multiple imputations conducted using NORM software prior to conducting the multiple regression analyses (Schafer 1999). By using an iterative method based on an estimation maximisation (EM) algorithm, NORM draws values from the conditional distribution of the variables, which are estimated based on available observations from the original data set (for technical details, see Schafer 1999). Following recommendations, we generated 100 possible data sets, which were then merged taking into account between-set and within-set standard errors. Both full information maximum likelihood estimation and multiple imputation have been shown to yield robust estimates under different conditions of missing data (Graham 2009).

\section{Ethical consideration}

This study was approved by the Ethics Review Board of Université de Montréal's Faculty of Arts and Science (reference 2008-179, 2696).

\section{Results \\ Trajectories}

To ensure that our classroom engagement scale provided an equivalent assessment of the construct at the different time points, we began by testing longitudinal measurement invariance from Grades 1 to 4 using the steps outlined by Byrne and Stewart (2006). Invariance was reached for all steps. To address our first objective, we used growth mixture modelling to estimate classroom engagement trajectories between kindergarten and fourth grade through Mplus software. Parameters were obtained by maximum likelihood estimation using an expectation maximisation algorithm (Muthén et al. 1987). As reported in Table 1, the Akaike information criterion (AIC), Bayesian information criterion and sample-size-adjusted Bayesian information criterion (SSBIC) favoured a three-class quadratic solution. The fit criteria for the three-group quadratic model were good $(\mathrm{AIC}=10823.94$ and SSBIC $=10870.01)$, corresponding to a low $(9 \%$, of which $26 \%=$ girls and $74 \%=$ boys $)$, medium $(19 \%$, of which $44 \%=$ girls and $56 \%=$ boys $)$ and high trajectory $(72 \%$, of which $57 \%$ = girls and $43 \%=$ boys $)$. As an indicator of model fit, we also examined entropy, which was 0.71 for our selected model and which was slightly higher than the entropy observed for the other models (Ramaswamy et al. 1993). Next, we examined the bootstrap likelihood ratio test because it has been shown to provide
TABLE 1: Growth mixture models of developmental patterns of engagement with linear and quadratic growth terms.

\begin{tabular}{lllll}
\hline Fit indices & 2 Class linear & 2 Class quadratic & 3 Class linear & 3 Class quadratic \\
\hline AIC & 11037.02 & 10957.30 & 10935.04 & 10823.94 \\
BIC & 11101.470 & 11048.61 & 110515.60 & 10936.73 \\
SSBIC & 11063.35 & 10994.60 & 10967.95 & 10870.01 \\
Entropy & 0.76 & 0.73 & 0.74 & 0.71 \\
Log likelihood & -5506.51 & -5461.66 & -5452.52 & -5390.97 \\
\hline
\end{tabular}

AIC, Akaike information criterion; BIC, Bayesian information criterion; SSBIC, sample-sizeadjusted Bayesian information criterion.

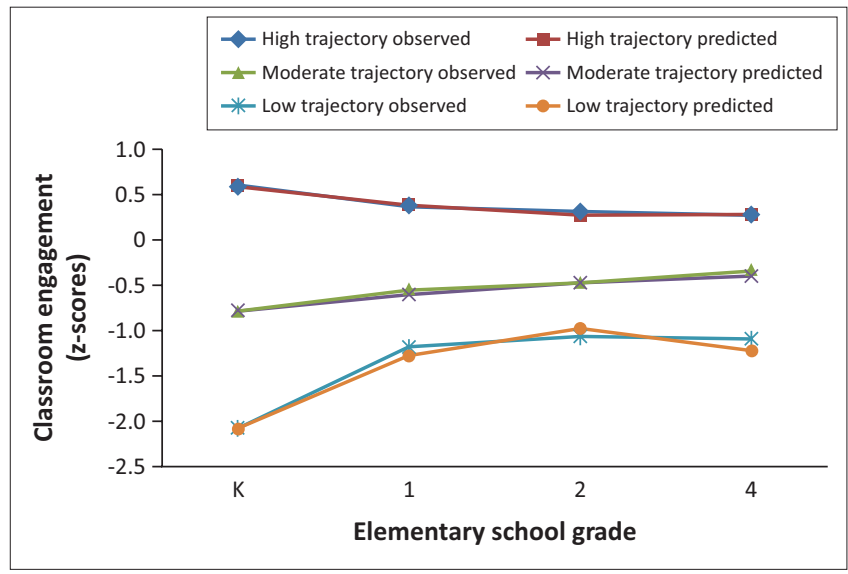

FIGURE 1: Classroom engagement trajectories from kindergarten to Grade 4.

reliable estimates of model fit. The observed $p$-value comparing a three- to two-class model quadratic model was smaller than 0.0001, suggesting a significantly better fit for the three-class quadratic model. There was no significant improvement in fit from a three- to four-class model. As a result, we selected a three-class quadratic model for its statistical fit and because it was consistent with prior research examining trajectories of classroom engagement across elementary school (Pagani, Fitzpatrick \& Parent 2012). The average posterior class probabilities for the low, medium and high trajectories were $0.90,0.74$ and 0.83 , respectively. The posterior mean fitted and observed values for the trajectories in primary school are illustrated in Figure 1. Descriptive statistics according to group membership are presented in Table 2 .

\section{Regression analysis}

Bivariate correlations between the main predictors and classroom engagement scores are presented in Table 3. In terms of regression analyses, Table 4 reports the relationship between child and family predictors and profiles of classroom engagement during primary school. All models control for child sex, prosocial skills, emotional distress and math and reading skills, as well as family configuration and socioeconomic status. All odds ratios are interpreted using 'low engagement' as the reference group. The Negelkerke $r$-squared was 0.22 , suggesting that our model accounted for a modest amount of the variance in the observed trajectories. In terms of the second objective, a one-point increase in the working memory scores corresponded to $35 \%$ greater odds of belonging to the high engagement group. Conversely, a onepoint increase on the impulsivity scale was associated with a $43 \%$ reduction in the probability of belonging to the high 
TABLE 2: Descriptive statistics for independent, dependent and control variables according to trajectory membership.

\begin{tabular}{|c|c|c|c|c|c|c|}
\hline \multirow[t]{2}{*}{ Engagement trajectory } & \multicolumn{2}{|c|}{ High $(N=1151)$} & \multicolumn{2}{|c|}{ Modefrate $(N=297)$} & \multicolumn{2}{|c|}{ Low $(N=141)$} \\
\hline & $M$ & SD & $M$ & SD & $M$ & SD \\
\hline \multicolumn{7}{|l|}{ Classroom engagement } \\
\hline Kindergarten (74 mo) & 2.92 & 0.11 & 2.38 & 0.16 & 1.86 & 0.18 \\
\hline Grade 1 (86 mo) & 4.23 & 0.51 & 3.53 & 0.64 & 3.02 & 0.62 \\
\hline Grade 2 (98 mo) & 4.22 & 0.55 & 3.65 & 0.64 & 3.09 & 0.55 \\
\hline Grade 4 (120 mo) & 3.21 & 0.59 & 2.78 & 0.61 & 2.12 & 0.73 \\
\hline Working memory (35 mo) & 1.25 & 0.70 & 1.10 & 0.66 & 0.99 & 0.66 \\
\hline Impulsivity (59 mo) & 3.47 & 1.71 & 4.31 & 1.80 & 5.03 & 1.76 \\
\hline Maternal hostility (59 mo) & 2.83 & 1.02 & 3.09 & 1.13 & 3.41 & 1.10 \\
\hline Maternal stress (53 mo) & 2.74 & 0.75 & 2.62 & 0.66 & 2.77 & 0.70 \\
\hline Social support (53 mo) & 9.16 & 1.33 & 9.00 & 1.42 & 8.68 & 1.60 \\
\hline Maternal warmth (59 mo) & 6.23 & 0.98 & 6.24 & 0.94 & 6.33 & 1.01 \\
\hline \multicolumn{7}{|l|}{ Control variables } \\
\hline Sex & 0.43 & 0.50 & 0.56 & 0.50 & 0.74 & 0.44 \\
\hline Number knowledge (65 mo) & 9.76 & 4.13 & 8.18 & 3.80 & 7.24 & 4.07 \\
\hline Receptive vocabulary (65 mo) & 67.58 & 18.49 & 60.59 & 18.93 & 56.31 & 20.31 \\
\hline Emotional distress (59 mo) & 1.93 & 1.27 & 1.80 & 1.30 & 1.89 & 1.33 \\
\hline Prosocial skills (59 mo) & 6.41 & 2.37 & 6.36 & 2.37 & 6.51 & 2.26 \\
\hline Family configuration (17 mo) & 0.24 & 0.42 & 0.29 & 0.45 & 0.40 & 0.49 \\
\hline Socio-economic status (5-65 mo) & 0.15 & 1.00 & -1.33 & 0.98 & -0.43 & 0.83 \\
\hline
\end{tabular}

mo, months; $M$, mean; SD, Standard deviation.

TABLE 3: Intercorrelations between predictors and classroom engagement in elementary school.

\begin{tabular}{|c|c|c|c|c|c|c|c|c|c|c|c|}
\hline Variables & 1 & 2 & 3 & 4 & 5 & 6 & 7 & 8 & 9 & 10 & 11 \\
\hline 1. CE kindergarten & $---\dagger$ & $0.58 * * *$ & $0.52 * * *$ & $0.49 * * *$ & $0.15 * * *$ & $-0.32 * * *$ & $-0.20 * * *$ & $0.11 * *$ & -0.030 & $0.11 * * *$ & 0.02 \\
\hline 2. CE grade 1 & - & $---\dagger$ & $0.68 * * *$ & $0.56 * * *$ & $0.16 * * *$ & $-0.32 * * *$ & $-0.19 * * *$ & $0.16 * * *$ & 0.01 & $0.10 * * *$ & 0.02 \\
\hline 3. CE grade 2 & - & - & ---+ & $0.63 * * *$ & $0.18 * * *$ & $-0.32 * * *$ & $-0.17 * * *$ & $0.13 * * *$ & 0.00 & $0.10 * * *$ & 0.03 \\
\hline 4. CE grade 4 & - & - & - & $---\dagger$ & $0.15 * * *$ & $-0.24 * * *$ & $-0.13^{* * *}$ & $0.15 * * *$ & -0.02 & $0.07 *$ & 0.02 \\
\hline 5. Working memory & - & - & - & & --+ & $-0.082 * *$ & 0.02 & 0.05 & 0.01 & 0.04 & -0.02 \\
\hline 6. Impulsivity & - & - & - & - & - & $---\dagger$ & $0.38 * * *$ & $-0.24 * * *$ & -0.04 & $-0.10 * * *$ & $-0.17 * * *$ \\
\hline 7. Maternal hostility & - & - & - & - & - & - & --+ & $-0.25 * * *$ & $-0.13 * * *$ & $-0.11 * * *$ & $-0.24 * * *$ \\
\hline 8. Maternal discipline & - & - & - & - & - & - & - & $---\dagger$ & $0.16 * * *$ & $0.10 * * *$ & $0.11 * * *$ \\
\hline 9. Maternal warmth & - & - & - & - & - & - & - & - & $---\dagger$ & $0.15^{* * *}$ & $0.18^{* * *}$ \\
\hline 10. Social support & - & - & - & - & - & - & - & - & - & $---\dagger$ & $0.12 * * *$ \\
\hline 11. Maternal stress & - & - & - & - & - & - & - & - & - & - & $---\dagger$ \\
\hline
\end{tabular}

$\mathrm{CE}$, classroom engagement.

$*, p<0.05 ; * *, p<0.01 ;$ and ${ }^{* * *}, p<0.00$.

$\dagger$, Variable was not included in a specific model. It is a standard notation.

TABLE 4: Predictors of classroom engagement trajectories membership.

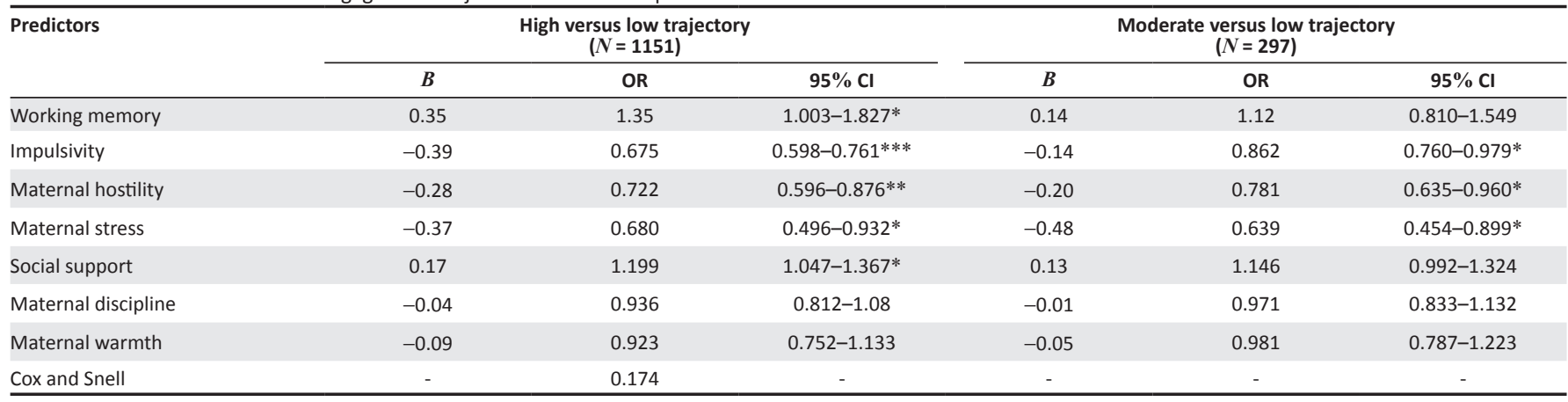

Note: Models include child sex, prosocial skills, emotional distress, math and reading skills, family configuration and socio-economic status.

$\mathrm{OR}$, odds ratio; $\mathrm{Cl}$, confidence interval; $B$, standardized regression coefficient.

Asterisks represent probability: $*, p<0.05 ;{ }^{* *}, p<0.01$; and ${ }^{* *}, p<0.001$.

engagement group. Scores of impulsivity were also associated with a $14 \%$ decrease in the probability of membership to the moderate engagement group.
In terms of objective 3, maternal hostility was independently associated with a $27 \%$ and $22 \%$ reduction in the odds of belonging to the high and moderate engagement groups, 
respectively. Mother self-reported social support was associated with $20 \%$ greater odds of belonging to the high engagement group. Finally, maternal stress was associated with a $30 \%$ and $44 \%$ decrease in the probability of being in the high and moderate engagement groups, respectively.

\section{Discussion}

In the present study, we observed naturally occurring individual differences in classroom engagement from kindergarten to the end of elementary school. In our sample of typically developing children, discrete subgroups showed stable high, moderate and low levels of classroom engagement. Most children appeared to follow a steady high trajectory of engagement. However, two minority subgroups of children (accounting for $26 \%$ of the sample) followed moderate or low trajectories of engagement. Our predictors accounted for $22 \%$ of the variance in classroom engagement, which represents a modest association. Nevertheless, given the tremendous cost of poor achievement and eventual dropout, identifying factors that account for even a small proportion of the variance in children's long-term academic success can be useful for the development of preventive interventions.

The observation of high, moderate and low trajectories of engagement replicates the findings of Pagani et al. (2012) who used an urban sample of disadvantaged youth from the same province to study engagement trajectories. Dominguez et al. (2010) found that children tend to show a steady decline in engagement in the early school years. However, their study employed a variable-centred approach. As such, given the methodological design of their study, it was not possible to examine whether population heterogeneity exists in children's developmental pathways. Together, the present findings and those of Pagani et al. (2012) shed light on the presumed natural course of engagement in typically developing students of elementary school age.

Preschoolers who were better able to keep information in working memory and who showed lower levels of impulsivity were more likely to remain organised and follow rules and procedures throughout elementary school. These prospective associations remained significant after children's math skills, reading and family socio-economic status were considered. As a result, our findings are consistent with those of other studies showing a robust and unique association between school entry cognitive control and academic performance (Blair \& Razza 2007; Fitzpatrick \& Pagani 2012; Matthews, Ponitz \& Morrison 2009; Rimm-Kaufman et al. 2009). Furthermore, the positive contribution of cognitive regulation skills was observed regardless of family risk variables, which suggests that targeting these skills in vulnerable children might represent an effective strategy for improving academic success.

In addition to these child-level skills, experiencing hostile parenting, higher parental stress and lower parental social support was related to less adaptive patterns of engagement in children. These results are consistent with allostatic load theories, according to which the experience of toxic stress and family adversity during the formative childhood years can lead to enduring alterations in central nervous system functioning (Blair et al. 2011; Repetti, Robles \& Reynolds 2011). Such alternations, in turn, have been linked to poor cognitive and self-regulation outcomes in children (Suor et al. 2015).

These findings relating the larger family context with child trajectories of school engagement also make sense from an ecological perspective (Bronfenbrenner 1986). Stress and low social support are likely to negatively influence the amount of psychological and social resources available to mothers, which may then compromise caregiving (Ensor \& Hughes 2010). Through playtime and reciprocal interactions, parents foster learning environments that help prepare children for the more formal learning that takes place in the classroom (Bernier, Carlson \& Whipple 2010; Mezzacappa 2004). As a result, highly stressed parents who also possess fewer social resources may have more difficult time providing children with the types of environments that foster strong cognitive skills.

Early childhood parental warmth and consistent use of discipline were not statistically associated with subsequent patterns of engagement. Our results are consistent with a recent study in which the sustained attention skills of poor and nearly poor children were predicted by maternal hostility but not maternal warmth (Razza et al. 2010). One possibility is that specific features of positive parenting, unmeasured in the present study, are likely to benefit the development of learning behaviour. For example, parenting practices that enhance child autonomy may be especially important for promoting engagement by contributing to the development of self-regulation and sustained attention skills in youngsters (Bernier et al. 2010; Kochanska, Philibert \& Barry 2009). Maternal warmth and discipline, on the other hand, may be especially important for children's development of positive emotional adjustment and social competence (Davidov \& Grusec 2006; Steelman et al. 2002).

This study has several limitations. Firstly, we observed naturally occurring individual differences using a correlational longitudinal design. Consequently, the present design does not allow us to determine with certainty the presence of a causal relationship between our predictor and outcome variables. Nevertheless, several potential confounders, such as preschool reading and math skills and family socioeconomic status, were ruled out. As in most longitudinal studies, differential sample attrition might have also compromised our ability to generalise the present findings to the general population with absolute certainty. To reduce the influence of selection bias on our results, we included variables associated with attrition in our analyses and employed best practices for handling missing data (Cummings 2013; Graham 2009). Finally, it was not possible to examine all variables of interest in this study. In particular, the present study would have benefited from the inclusion of additional indicators of parent-child interactions, such as 
child attachment quality, parent-child reinforcement patterns and maternal autonomy promotion.

Cognitive control and family adversity are both promising intervention targets. Accumulating evidence suggests that high-quality preschool education improves children's cognitive control and self-regulation. Furthermore, these programmes appear to be effective with disadvantaged children (Blair \& Raver 2014; Diamond et al. 2007; Lillard \& Else-Quest 2006). Prior studies have also shown the effectiveness of providing support to parents as a means of reducing family adversity and improving young children's cognitive outcomes (Olds et al. 2004, 2014).

The learning skills children possess on the first day of school are shaped prior to school entry through a confluence of individual child and contextual factors. In the present study, we observed stability in the trajectories of child engagement from school entry towards emerging adolescence. A better understanding of how early childhood dispositions that reflect cognitive and attention control contribute to subsequent classroom engagement is useful for understanding the potential benefit of targeting such self-regulatory skills during the preschool years. Furthermore, our results suggest that early family context additionally contributes to child academic outcomes across elementary school. Accordingly, we propose that broader school readiness interventions that consider the early caretaking environment in addition to child skills can represent a promising strategy for improving academic outcomes in at-risk children.

\section{Acknowledgements Competing interests}

The authors have declared that no competing interests exist.

\section{Author's contributions}

All authors contributed equally to this work.

\section{Funding information}

The Quebec Longitudinal Study of Child Development (QLSCD) was supported by funding from the Quebec Government's Ministry of Health, Ministry of Education, Ministry of Family Affairs, the Lucie and Andre Chagnon Foundation, the Robert-Sauve Research Institute of Health and Security at Work and the Quebec Statistics Institute (ISQ).

\section{Data availability statement}

Data sharing is not applicable to this article as no new data were created or analysed in this study.

\section{Disclaimer}

The views and opinions expressed in this article are those of the authors and do not necessarily reflect the official policy or position of any affiliated agency of the authors.

\section{References}

Achenbach, T.M., Edelbrock, C. \& Howell, C.T., 1987, 'Empirically based assessment of the behavioral/emotional problems of 2-and 3-year-old children', Journal of Abnormal Child Psychology 15, 629-650. https://doi.org/10.1007/BF00917246

Alp, I.E., 1994, 'Measuring the size of working memory in very young children: The imitation sorting task', International Journal of Behavioral Development 17(1), 125-141. https://doi.org/10.1177/016502549401700108

Arnsten, A.F., 2009, 'Stress signalling pathways that impair prefrontal cortex structure and function', Nature Reviews Neuroscience 10(6), 410-422. https://doi. org/10.1038/nrn2648

Barrera, M. \& Garrison-Jones, C., 1992, 'Family and peer social support as specific correlates of adolescent depressive symptoms', Journal of abnormal child psychology 20(1), 1-16.

Bernier, A., Carlson, S. \& Whipple, N., 2010, 'From external regulation to self-regulation: Early parenting precursors of young children's executive functioning', Child Development 81(1), 326-339. https://doi.org/10.1111/j.1467-8624.2009.01397.x

Blair, C., Granger, D.A., Willoughby, M., Mills-Koonce, R., Cox, M., Greenberg, M. et al., 2011, 'Salivary cortisol mediates effects of poverty and parenting on executive functions in early childhood', Child Development 82(6), 1970-1984. https://doi. org/10.1111/j.1467-8624.2011.01643.x

Blair, C. \& Raver, C.C., 2014, 'Closing the achievement gap through modification of neurocognitive and neuroendocrine function: Results from a cluster randomized controlled trial of an innovative approach to the education of children in kindergarten', PLoS One 9(11), e112393. https://doi.org/10.1371/journal. pone.0112393

Blair, C. \& Razza, R.P., 2007, 'Relating effortful control, executive function, and false belief understanding to emerging math and literacy ability in kindergarten', Child Development 78(2), 647-663. https://doi.org/10.1111/j.1467-8624.2007.01019.x

Boivin, M., Pérusse, D., Dionne, G., Saysset, V., Zoccolillo, M., Tarabulsy, G.M. et al., 2005, 'The genetic-environmental etiology of parents' perceptions and selfassessed behaviours toward their 5-month-old infants in a large twin and singleton sample', The Journal of Child Psychology and Psychiatry 46(6), 612-630. https://doi.org/10.1111/j.1469-7610.2004.00375.x

Bornstein, M.H. \& Bradley, R.H., 2003, Socioeconomic status, parenting, and child development, Lawrence Erlbaum, Mahwah, NJ.

Broidy, L.M., Nagin, D.S., Tremblay, R.E., Bates, J.E., Brame, B., Dodge, K.A. et al., 2003, 'Developmental trajectories of childhood disruptive behaviors and adolescent delinquency: A six-site, cross-national study', Developmental Psychology 39(2), 222. https://doi.org/10.1037/0012-1649.39.2.222

Bronfenbrenner, U., 1986, 'Ecology of the family as a context for human development: Research perspectives', Developmental Psychology 22(6), 723-742. https://doi. org/10.1037/0012-1649.22.6.723

Bull, R. \& Lee, K., 2014, 'Executive functioning and mathematics achievement', Child Development Perspectives 8(1), 36-41.

Burchinal, M.R., Follmer, A. \& Bryant, D.M., 1996, 'The relations of maternal social support and family structure with maternal responsiveness and child outcomes among African American families', Developmental Psychology 32(6), 1073-1083. https://doi.org/10.1037/0012-1649.32.6.1073

Byrne, B.M. \& Stewart, S.M., 2006, 'Teacher's corner: The MACS approach to testing for multigroup invariance of a second-order structure: A walk through the process', Structural equation modeling 13(2), 287-321.

Champagne, F.A. \& Curley, J.P., 2009, 'Epigenetic mechanisms mediating the longterm effects of maternal care on development', Neuroscience \& Biobehavioral Reviews 33(4), 593-600. https://doi.org/10.1016/j.neubiorev.2007.10.009

Cohen, S., Tyrrell, D.A. \& Smith, A.P., 1993, 'Negative life events, perceived stress, negative affect, and susceptibility to the common cold', Journal of Personality and Social Psychology 64(1), 131. https://doi.org/10.1037/0022-3514.64.1.131

Cummings, P., 2013, 'Missing data and multiple imputation', JAMA Pediatrics 167(7), 656-661. https://doi.org/10.1001/jamapediatrics.2013.1329

Daniel, G.R., Wang, C. \& Berthelsen, D., 2016, 'Early school-based parent involvement, children's self-regulated learning and academic achievement: An Australian longitudinal study', Early Childhood Research Quarterly 36, 168-177. https://doi. org/10.1016/j.ecresq.2015.12.016

Davidov, M. \& Grusec, J.E., 2006, 'Untangling the links of parental responsiveness to distress and warmth to child outcomes', Child Development 77(1), 44-58. https:// doi.org/10.1111/j.1467-8624.2006.00855.x

Dent, A.L. \& Koenka, A.C., 2016, 'The relation between self-regulated learning and academic achievement across childhood and adolescence: A meta-analysis', Educational Psychology Review 28(3), 425-474. https://doi.org/10.1007/s10648015-9320-8

Diamond, A., Barnett, W.S., Thomas, J. \& Munro, S., 2007, 'Preschool program improves cognitive control', Science 318(5855), 1387-1388. https://doi.org/10.1126/ science. 1151148

Dobkin, P.L., Tremblay, R.E., Masse, L.C. \& Vitaro, F., 1995, 'Individual and peer characteristics in predicting boys' early onset of substance abuse: A seven-year longitudinal study', Child Development 66(4), 1198-1214. https://doi.org/ $10.2307 / 1131807$

Dominguez, X., Vitiello, V.E., Maier, M.F. \& Greenfield, D.B., 2010, 'A longitudinal examination of young children's learning behavior: Child level and classroom leve predictors of change throughout the preschool year', School Psychology Review 39, 29-47.

Duncan, G.J., Dowsett, C.J., Claessens, A., Magnuson, K., Huston, A.C., Klebanov, P. et al., 2007, 'School readiness and later achievement', Developmental Psychology 43(6), 1428-1446. https://doi.org/10.1037/0012-1649.43.6.1428 
Dunn, L.M., Thériault-Whalen, C.M. \& Dunn, L.M., 1993, Échelle de vocabulaire en images Peabody: Adaptation française du Peabody Picture Vocabulary testrevised: Manuel pour les formes $A$ et $B$ [French adaptation of the Peabody Picture revised: Manuel pour les formes A et B [French adaptation of the Peabody
Vocabulary Test Revised: Manuals for Forms A and B], Psycan, Toronto.

Ensor, R. \& Hughes, C., 2010, 'With a little help from my friends: Maternal social support, via parenting, promotes willingness to share in preschoolers born to young mothers', Infant and Child Development 19(2), 127-141. https://doi.org/ young mothers',
$10.1002 /$ icd.643

Fitzpatrick, C. \& Pagani, L., 2012, 'Toddler working memory skills predict kindergarten school readiness', Intelligence 40(2), 205-212. https://doi.org/10.1016/j.intell. 2011.11.007

Fitzpatrick, C. \& Pagani, L., 2013, 'Task-oriented behavior pays off in later childhood' Journal of Developmental and Behavioral Pediatrics 34(2), 94-101. https://doi. org/10.1097/DBP.0b013e31827a3779

Fitzpatrick, C., Archambaut, I., Janosz, M. \& Pagani, L.S., 2015, 'Preschool working memory forecasts high school dropout risk', Intelligence 53, 160-165.

Graham, W.J., 2009, 'Missing data: Making it work in the real world', Annual Review of Psychology60,549-576. https://doi.org/10.1146/annurev.psych.58.110405.085530

Guinosso, S.A., Johnson, S.B. \& Riley, A.W., 2015, 'Multiple adverse experiences and child cognitive development', Pediatric Research 79(1-2), 220-226. https://doi. org/10.1038/pr.2015.195

Hackman, D. \& Farah, M., 2009, 'Socioeconomic status and the developing brain', Trends in Cognitive Sciences 13(2), 65-73. https://doi.org/10.1016/j.tics.2008.11.003

Hartman, H.J., 1998, 'Metacognition in teaching and learning: An introduction', Instructional Science 26(1-2), 1-3.

Jung, T. \& Wickrama, K.A., 2008, 'An introduction to latent class growth analysis and growth mixture modeling', Social and personality psychology compass 2(1), 302-317.

Kochanska, G., Philibert, R.A. \& Barry, R.A., 2009, 'Interplay of genes and early mother-child relationship in the development of self-regulation from toddler to preschool age', Journal of Child Psychology and Psychiatry 50(11), 1331-1338. https://doi.org/10.1111/j.1469-7610.2008.02050.x

Ladd, G.W. \& Dinella, L.M., 2009, 'Continuity and change in early school engagement: Predictive of children's achievement trajectories from first to eighth grade?',
Journal of Educational Psychology 101(1), 190-200. https://doi.org/10.1037/ Journal of

Levin, H., Belfield, C., Muennig, P. \& Rouse, C., 2007, The costs and benefits of an excellent education for all of America's children, Teacher's College, New York, NY.

Li-Grining, C.P., Votruba-Drzal, E., Maldonado-Carreno, C. \& Haas, K., 2010, 'Children's early approaches to learning and academic trajectories through fifth grade' Developmental Psychology 46, 1062-1077. https://doi.org/10.1037/a0020066

Lillard, A. \& Else-Quest, N., 2006, 'The early years: Evaluating Montessori education', Science 313(5795), 1893-1894. https://doi.org/10.1126/science.1132362

Lupien, S.J., Maheu, F., Tu, M., Fiocco, A. \& Schramek, T.E., 2007, 'The effects of stress and stress hormones on human cognition: Implications for the field of brain and cognition', Brain and Cognition 65(3), 209-237. https://doi.org/10.1016/j.bandc. 2007.02.007

Matthews, J.S., Ponitz, C.C. \& Morrison, F.J., 2009, 'Early gender differences in selfregulation and academic achievement', Journal of Educational Psychology 101(3), 689-704. https://doi.org/10.1037/a0014240

Mezzacappa, E., 2004, 'Alerting, orienting, and executive attention: Developmental properties and sociodemographic correlates in an epidemiological sample of
young, urban children', Child Development 75(5), 1373-1386. https://doi. young, urban children', Child Developm
org/10.1111/j.1467-8624.2004.00746.x

Muthén, B., Kaplan, D. \& Hollis, M., 1987, 'On structural equation modeling with data that are not missing completely at random', Psychometrika 52, 431-462. https:// doi.org/10.1007/BF02294365

Nagin, D. \& Tremblay, R.E., 1999, 'Trajectories of boys' physical aggression, opposition, and hyperactivity on the path to physically violent and nonviolent juvenile delinquency', Child Development 70(5), 1181-1196. https://doi.org/10.1111/ 1467-8624.00086

Offord, D.R., Boyle, M.H. \& Racine, Y., 1989, 'Ontario child health study: Correlates of disorder', Journal of the American Academy of Child \& Adolescent Psychiatry 28(6), 856-860. https://doi.org/10.1097/00004583-198911000-00008

Okamoto, Y. \& Case, R., 1996, 'Exploring the microstructure of children's central conceptual structures in the domain of number', Monographs of the Society for Research in Child Development 61(1-2), 27-58. https://doi.org/10.1111/j.15405834.1996.tb00536.x

Olds, D.L., Holmberg, J.R., Donelan-McCall, N., Luckey, D.W., Knudtson, M.D. \& Robinson, J., 2014, 'Effects of home visits by paraprofessionals and by nurses on children: Follow-up of a randomized trial at ages 6 and 9 years', JAMA Pediatrics 168(2), 114-121. https://doi.org/10.1001/jamapediatrics.2013.3817

Olds, D.L., Robinson, J., Pettitt, L., Luckey, D.W., Holmberg, J., Ng, R.K. et al., 2004 'Effects of home visits by paraprofessionals and by nurses: Age 4 follow-up results of a randomized trial', Pediatrics 114(6), 1560-1568. https://doi.org/10.1001/ jamapediatrics.2013.3817

Pagani, L.S., Fitzpatrick, C., Archambault, I. \& Janosz, M., 2010, 'School readiness and later achievement: A French Canadian replication and extension', Developmental Psychology 46(5), 984-994. https://doi.org/10.1037/a0018881

Pagani, L.S., Fitzpatrick, C. \& Parent, S., 2012, 'Relating kindergarten attention to subsequent developmental pathways of classroom engagement in elementary school', Journal of Abnormal Child Psychology 40, 715-725. https://doi.org/ 10.1007/s10802-011-9605-4
Pagani, L.S., Tremblay, R.E., Vitaro, F., Boulerice, B. \& McDuff, P., 2001, 'Effects of grade retention on academic performance and behavioral development', Development andPsychopathology13(2),297-315. https://doi.org/10.1017/S0954579401002061

Ponitz, C.C., McClelland, M.M., Matthews, J.S. \& Morrison, F.J., 2009, 'A structured observation of behavioral self-regulation and its contribution to kindergarten outcomes', Developmental Psychology 45(3), 605-619. https://doi.org/10.1037/ a0015365

Ramaswamy, V., DeSarbo, W., Reibstein, D. \& Robinson, W., 1993, 'An empirical pooling approach for estimating marketing mix elasticities with PIMS data', Marketing Science 12(1), 103-124. https://doi.org/10.1287/mksc.12.1.103

Ram, N. \& Grimm, K.J., 2009, 'Methods and measures: Growth mixture modeling: A method for identifying differences in longitudinal change among unobserved groups', International Journal of Behavioral Development 33(6), 565-576. https:// doi.org/10.1177/0165025409343765

Razza, R.A., Martin, A. \& Brooks-Gunn, J., 2010, 'Associations among family environment, sustained attention, and school readiness for low-income children Developmental Psychology 46(6), 1528-1542. https://doi.org/10.1037/a0020389

Reeve, J. \& Lee, W., 2014, 'Students' classroom engagement produces longitudinal changes in classroom motivation', Journal of Educational Psychology 106(2), $527-$ 540. https://doi.org/10.1037/a0034934

Repetti, R.L., Robles, T.F. \& Reynolds, B., 2011, 'Allostatic processes in the family', Development and Psychopathology 23(3), 921-938. https://doi.org/10.1017/ S095457941100040X

Richters, J.E., 1997, 'The Hubble hypothesis and the developmentalist's dilemma' Development and Psychopathology 9(2), 193-229. https://doi.org/10.1017/ Development and
S0954579497002022

Rimm-Kaufman, S.E., Curby, T.W., Grimm, K.J., Nathanson, L. \& Brock, L.L., 2009, 'The contribution of children's self-regulation and classroom quality to children's adaptive behaviors in the kindergarten classroom', Developmental Psychology 45(4), 958. https://doi.org/10.1037/a0015861

Robles, T.F., Carroll, J.E., Bai, S., Reynolds, B.M., Esquivel, S. \& Repetti, R.L., 2016, 'Emotions and family interactions in childhood: Associations with leukocyte telomere length', Psychoneuroendocrinology 63, 343-350. https://doi.org/10.1016/ j.psyneuen.2015.10.018

Rutter, M. \& O'Connor, T.G., 2004, 'Are there biological programming effects for psychological development? Findings from a study of Romanian adoptees', Developmental Psychology 40(1), 81-94. https://doi.org/10.1037/0012 1649.40.1.81

Sameroff, A., 2010, 'A unified theory of development: A dialectic integration of nature and nurture', Child Development 81(1), 6-22. https://doi.org/10.1111/j.1467-8624. 2009.01378.x

Sasser, T.R., Bierman, K.L. \& Heinrichs, B., 2015, 'Executive functioning and schoo adjustment: The mediational role of pre-kindergarten learning-related behaviors', Early Childhood Research Quarterly 30, 70-79. https://doi.org/10.1016/j. ecresq.2014.09.001

Schafer, J.L., 1999, 'Multiple imputation: A primer', Statistical Methods in Medical Research 8(1), 3-15. https://doi.org/10.1177/096228029900800102

Schieve, L.A., Blumberg, S.J., Rice, C., Visser, S.N. \& Boyle, C., 2007, 'The relationship between autism and parenting stress', Pediatrics 119(Suppl. 1), S114-S121. https://doi.org/10.1542/peds.2006-2089Q

Shonkoff, J., 2011, 'Protecting brains, not simply stimulating mind', Science 333(6045), 982-983. https://doi.org/10.1126/science.1206014

Sodian, B. \& Frith, U., 2008, 'Metacognition, theory of mind, and self-control: The relevance of high-level cognitive processes in development, neuroscience, and education', Mind, Brain, and Education 2(3), 111-113. https://doi.org/10.1111/ education', Mind, Brain, and
j.1751-228X.2008.00040.x

Steelman, L.M., Assel, M.A., Swank, P.R., Smith, K.E. \& Landry, S.H., 2002, 'Early maternal warm responsiveness as a predictor of child social skills: Direct and indirect paths of influence over time', Journal of Applied Developmental Psychology 23(2), 135-156. https://doi.org/10.1016/S0193-3973(02)00101-6

Stetser, M.C. \& Stillwell, R., 2014, Public high school four-year on-time graduation rates and event dropout rates: School years 2010-11 and 2011-12, First Look, NCES 2014-391, National Center for Education Statistics.

Suor, J.H., Sturge-Apple, M.L., Davies, P.T., Cicchetti, D. \& Manning, L.G., 2015, 'Tracing differential pathways of risk: Associations among family adversity, cortisol, and cognitive functioning in childhood', Child Development 86(4), 1142-1158. https:// doi.org/10.1111/cdev.12376

Tobin, K. \& Tippins, D.J., 1993, 'Constructivism as a referent for teaching and learning', in K. Tobin (ed.), The practice of constructivism in science education, pp. 3-21, American Association for the Advancement of Science, Washington, DC.

Tremblay, R.E., Pihl, R.O., Vitaro, F. \& Dobkin, P.L., 1994, 'Predicting early onset of male antisocial behavior from preschool behavior', Archives of General Psychiatry 51(9), 732-739. https://doi.org/10.1001/archpsyc.1994.03950090064009

Uppal, S., 2017, Young men and women without a high school diploma, Statistics Canada, Insights on Canadian Society, Statistics Canada, ISSN 2291-0840.

Wade, M., Moore, C., Astington, J.W., Frampton, K. \& Jenkins, J.M., 2015, 'Cumulative contextual risk, maternal responsivity, and social cognition at 18 months', Development and Psychopathology 27(01), 189-203. https://doi.org/10.1017/ S0954579414000674

Wang, M.T. \& Fredricks, J.A., 2014, 'The reciprocal links between school engagement, youth problem behaviors, and school dropout during adolescence', Child Development 85(2), 722-737. https://doi.org/10.1111/cdev.12138 